\title{
Better memory for intrinsic versus extrinsic details underlies the enhanced recollective experience of negative events
}

\author{
Mariela Mihaylova, ${ }^{1,2}$ Patrik Vuilleumier, ${ }^{1,3,4}$ and Ulrike Rimmele ${ }^{1,5}$ \\ ${ }^{1}$ Department of Basic Neurosciences, University of Geneva, 1202 Geneva, Switzerland; ${ }^{2}$ Faculty of Psychology and Educational Sciences, \\ University of Geneva, 1211 Geneva, Switzerland; ${ }^{3}$ Swiss Center for Affective Sciences, University of Geneva, 1202 Geneva, Switzerland; \\ ${ }^{4}$ Neurology Department, University Hospital Geneva, 1205 Geneva, Switzerland; ${ }^{5}$ Center for the Interdisciplinary Study of Gerontology \\ and Vulnerability, University of Geneva 1205 Geneva, Switzerland
}

\begin{abstract}
Why we remember emotional events with an increased subjective sense of remembering (SSR) is unclear. SSR for neutral events is linked to memory for various kinds of details. Using the Remember/Know paradigm, participants provided written justifications of their Remember responses indicating what they specifically recollected about a negative or neutral photo seen during encoding. Crucially, Remember responses for negative photos were more often linked to memory for details of the stimuli (intrinsic details) versus details related to external associations (extrinsic details) or emotional reaction at encoding, suggesting that memory for intrinsic details underlies the enhanced SSR of negative stimuli.
\end{abstract}

The exhilaration of your first plane ride. The chilling accident you drove by on the highway. Recalling events like these, we usually reexperience the episode vividly with many details in mind (Tulving 1985). This conscious reliving of past events, that is, the subjective sense of remembering (SSR), is typically enhanced by emotion (Talarico and Rubin 2003; Sharot et al. 2007a). Yet this enhanced SSR does not always correspond to better memory for details, even though it is often assumed that enhanced confidence is related to higher memory accuracy, for example, in eyewitness testimonies (Deffenbacher 1980). This begs the question: What accounts for the enhanced SSR of emotional events? Here, we examine how memory for stimulus details versus other details and emotional reaction underlie the enhanced SSR for negative versus neutral stimuli.

To measure SSR, the Remember/Know paradigm is used in experimental settings (Tulving 1985). A "Remember" response indicates recognition memory accompanied by the conscious recollection of contextual details of a particular episode, whereas memory without specific conscious recollection from the time of the episodic occurrence corresponds to a "Know" response. In experimental contexts, participants consistently show higher Remember responses for emotional compared with neutral stimuli (Ochsner 2000; Kensinger and Corkin 2003; Sharot et al. 2004, 2007b; Dolcos et al. 2005; Sharot and Yonelinas 2008; Rimmele et al. 2012).

For neutral stimuli, it has been demonstrated that stimuli judged as "Remembered" versus "Known" are accompanied by enhanced memory for a variety of contextual details, such as temporal order, spatial location, visual appearance, or internal and external associations (Perfect et al. 1996; Gardiner et al. 1998). In Gardiner et al. (1998), participants' subjective justifications of Remember responses to neutral word stimuli revealed two broad types of recollected detail categories linked to Remember responses. One type, list-reference, included specific recollections about the study item, such as the spelling or position of the word during

\section{Corresponding author: ulrike.rimmele@unige.ch}

Article is online at http://www.learnmem.org/cgi/doi/10.1101//m.049734.119. the presentation. The other type, termed self-reference, reflected memory about the previously studied word triggering some personal memory during the time of the study (Gardiner et al. 1998). Taken together, these studies offer proof for a link between the SSR of neutral stimuli and memory for contextual details mostly relating to the studied item itself or personal associations.

However, it is unclear how SSR of emotional items relates to memory for details of the studied items versus other kinds of details. While previous research suggests a link between enhanced memory for emotional stimuli and memory-narrowing effects, leading to a focal, or intrinsic, enhancement for specific features of the item in memory (Mather 2007; Kensinger 2009; Mather and Sutherland 2009), it is still unclear how memory for perceptual features of emotional items relates to their enhanced SSR. So far, experimental data demonstrates that the increased SSR of emotional stimuli is associated with increased accurate recollection of features inherently belonging to the stimuli, such as the time and place, but not features which are not inherent to the stimulus such as the color of a frame around the stimulus (Rimmele et al. 2011, 2012). These findings raise the question whether the enhanced SSR of emotional versus neutral stimuli is linked to better memory for details inherent to a stimulus (intrinsic details) rather than memory for extrinsic details, that is, details not inherent to the stimulus (e.g., personal thoughts the stimulus triggered).

An alternative explanation for the increased SSR may lie in the emotional reaction to emotional events. In particular, emotional events elicit subjective and physiological arousal that have been linked to increased memory vividness and increased SSR for emotional stimuli (Ochsner 2000; Kensinger and Corkin 2003; Bisby and Burgess 2014; Boywitt 2015; Rimmele et al. 2016; Antypa et al. 2018).

(C) 2019 Mihaylova et al. This article is distributed exclusively by Cold Spring Harbor Laboratory Press for the first 12 months after the full-issue publication date (see http://learnmem.cshlp.org/site/misc/terms.xhtml). After 12 months, it is available under a Creative Commons License (Attribution-NonCommercial 4.0 International), as described at http://creativecommons.org/licenses/by-nc/ $4.0 \%$. 
No prior research has qualitatively assessed whether different amounts of intrinsic versus extrinsic details versus emotional reaction recollection differentially underlie the SSR emotional versus neutral stimuli. To examine this question, we used the Remember/Know paradigm and asked participants to provide detailed explanations of what they remembered from the first encounter with the stimuli. These Remember justifications were then classified into three categories (intrinsic, extrinsic, and emotional reaction) that comprised key categories of previously established classification schemes to assess qualitative justifications of Remember responses for neutral stimuli (Perfect et al. 1996; Gardiner et al. 1998). Remember justifications which featured content inherent to the image such as visual appearance (Perfect et al. 1996) or item physical features (Gardiner et al. 1998) comprised our intrinsic category. On the other hand, details such as external associations (Perfect et al. 1996) and self-reference (Gardiner et al. 1998), such as participants' thoughts when viewing the photo, are extrinsic in our classification as they relate to details or associations external to the image. Justifications of Remember responses that contained the recall of participants' emotional reaction that they experienced during encoding were classified into the category emotional reaction. Hence, the aim of this study was to examine whether memory for intrinsic, extrinsic details and emotional reaction contribute differently to the SSR of emotional versus neutral stimuli, which might explain the well-established enhanced SSR of emotional stimuli.

The study sample consisted of 34 students ( 17 female) from the University of Geneva ( $23.06 \pm 0.55$ range: $18-31 \mathrm{yr})$. All participants provided written informed consent and were paid for their participation. The experiment was approved by the ethics committee at the University of Geneva.

Based on their normative arousal and valence ratings $(1=$ calm, 9 =xcited; 1 =unhappy, $9=$ happy; Lang et al. 2005), we chose two sets of 30 negative and two sets of 30 neutral photos from the International Affective Picture Set (IAPS). The sets were counterbalanced across study and test, that is, a set of photos used for encoding was a set of foils for the other half of participants. The two negative sets had higher arousal rating (Set 1: $5.78 \pm 0.56$, Set 2: $6.00 \pm 0.70$ ) than the two neutral sets (Set 1: $3.83 \pm 0.84$, Set 2 : $3.99 \pm 1.08 ; P \leq 0.001)$. Valence ratings were lower for negative photos (Set 1: $2.68 \pm 1.03$; Set 2: $2.44 \pm 0.70$ ) versus neutral photos (Set 1: $5.74 \pm 0.64$; Set $2: 5.57 \pm 1.03 ; P \leq 0.001$ ). Arousal and valence ratings did not differ between the two negative sets (all $P \geq$ 0.14 ) and the two neutral sets (all $P \geq 0.30$ ). In addition, negative and neutral stimuli did not differ in their physical characteristics (luminance, contrast, entropy, color, all $P \geq 0.15$; Table 1), which we computed as described in (Marchewka et al. 2014). Likewise, negative and neutral photos did not differ in their rating for their amount of elements $\left(t_{(18)}=0.90, P=0.38\right.$; see Table 1$)$, that we obtained from an additional group of 19 participants using a ninepoint scale rating referring to the number of objects $(1=$ very few, $9=$ a great many) (Marin and Leder 2016).

During encoding of 60 photos (three blocks of 20 photos), participants were instructed to look at each photo during 4000 msec followed by a white fixation cross of $1000 \mathrm{msec}$ before the presentation of the next photo. One hour after encoding, participants did a practice session that ensured their understanding of the Remember/Know distinction based on previous examples (Rajaram 1993; Yovel and Paller 2004) and then underwent the recognition test consisting of six blocks of 20 photos. Each photo was presented for $2000 \mathrm{msec}$ followed by a Remember/Know/New judgment. After each Remember response, participants were instructed to provide a written justification explaining what they remembered specifically from seeing this photo previously (Curran et al. 1997). Justifications of Remember responses were classified into three categories, as shown in Table 2 . Raters were instructed to place a " 1 " beside responses that fit a category and " 0 " next to explanations that did not fit the category (Curran et al. 1997). If a response contained any combination of the three categories (15.95\% of all Remember hits), the "1" was split across the respective categories (see Gardiner et al. 1998). If the explanation was a combination of two categories each category was given 0.5 points. If the justification was a combination of all categories, each category was allocated $1 / 3$ of a point. Inter-rater reliability was 0.90 for all categories combined. We then calculated the percentage of how many Remember responses were accompanied by each category for each rater and then averaged the percentages from both raters. The raters were not able to classify $1.15 \%$ of Remember hits, as the explanations did not contain qualitative recollective information.

Participants showed an enhanced SSR $\left(R_{\text {hit rate }}-R_{\text {false alarm rate }}\right)$ for negative $(0.77 \pm 0.03)$ versus neutral photos $\left(0.56 \pm 0.04 ; t_{(33)}=\right.$ $8.41, P<0.001, r=0.826,95 \%$ CI $[0.157,0.257]$; see Table 3$)$. In particular, a significant Response Type $\left(R_{\text {hit rate }} / R_{\text {false alarm rate }}\right) \times$ Emotion (Negative/Neutral) interaction in a $2 \times 2$ ANOVA $\left(F_{(1,33)}=\right.$ 70.66, $\left.P \leq 0.001, \eta^{2}=0.682\right)$ showed that participants provided significantly more correct Remember responses (higher $R_{\text {hit rate }}$ ) to negative $(0.78 \pm 0.03)$ versus neutral photos $(0.58 \pm 0.04$; $t_{(33)}=8.89, P<0.001, r=0.840,95 \%$ CI $\left.[0.160,0.255]\right)$, whereas $R_{\text {false alarm rate }}$ did not differ between negative and neutral photos, $P>0.82$. Contrariwise, a significant Response Type $\left(K_{\text {hit rate }} / K_{\text {false alarm rate }}\right) \times$ Emotion (Negative/Neutral) interaction in a $2 \times 2$ ANOVA $\left(F_{(1,33)}=27.30, P \leq 0.001, \eta^{2}=0.453\right)$ showed that participants provided significantly more correct Know responses (higher $K_{\text {hit rate }}$ ) to neutral $\left(0.22 \pm 0.03 ; t_{(33)}=5.62\right.$,

Table 1. Characteristics of negative and neutral photos

\begin{tabular}{|c|c|c|c|c|}
\hline & \multicolumn{2}{|c|}{ Negative } & \multicolumn{2}{|c|}{ Neutral } \\
\hline & $M$ & SE & $M$ & SE \\
\hline $\begin{array}{l}\text { Luminance } \\
\text { Contrast }\end{array}$ & $\begin{array}{l}87.17 \\
65.64\end{array}$ & $\begin{array}{l}3.91 \\
1.92\end{array}$ & $\begin{array}{l}84.12 \\
64.04\end{array}$ & $\begin{array}{l}4.36 \\
1.80\end{array}$ \\
\hline $\begin{array}{l}\text { Measures of image com } \\
\text { JPEG_size80 } \\
\text { JPEG_size50 } \\
\text { Entropy }\end{array}$ & $\begin{array}{l}121,006 \\
66,698 \\
6.79\end{array}$ & $\begin{array}{l}4999 \\
2977 \\
0.14\end{array}$ & $\begin{array}{l}131,578 \\
71,486 \\
6.82\end{array}$ & $\begin{array}{l}5436 \\
3326 \\
0.13\end{array}$ \\
\hline $\begin{array}{l}\text { Measures of color } \\
\text { LABL } \\
\text { LABA } \\
\text { LABB }\end{array}$ & $\begin{array}{l}36.78 \\
7.75 \\
10.77\end{array}$ & $\begin{array}{l}1.61 \\
1.00 \\
1.40\end{array}$ & $\begin{array}{l}35.40 \\
5.61 \\
8.81\end{array}$ & $\begin{array}{l}1.82 \\
1.28 \\
1.78\end{array}$ \\
\hline $\begin{array}{l}\text { Rating of stimuli }(\mathrm{N}=19 \\
\text { Amount of elements }\end{array}$ & $\begin{array}{l}y \mathrm{yr}, S D=5 . \\
3.77\end{array}$ & 0.19 & 3.81 & 0.19 \\
\hline
\end{tabular}


Table 2. Table outlining our definition of each category underlying participants' Remember responses, with corresponding examples chosen from participants

\begin{tabular}{|c|c|c|c|}
\hline Category & Definition & $\begin{array}{l}\text { Example: photo evoking a } \\
\text { Remember response }\end{array}$ & $\begin{array}{l}\text { Example: photo evoking a } \\
\text { Remember response }\end{array}$ \\
\hline Intrinsic & $\begin{array}{l}\text { Specific details of the photo itself, such as particular } \\
\text { items or colors }\end{array}$ & $\begin{array}{l}\text { Woman standing in rain } \\
\text { holding the umbrella }\end{array}$ & $\begin{array}{l}\text { "I remember it is raining and her } \\
\text { shoes and her black clothes." }\end{array}$ \\
\hline Extrinsic & $\begin{array}{l}\text { Details not belonging to the photo itself, for example, } \\
\text { participant's thoughts when viewing the photo }\end{array}$ & Men sitting outside a café & "It looks like a plaza in Geneva." \\
\hline Emotional reaction & Emotional reaction the photo had elicited & Dead woman on the ground & "I remember feeling disgusted." \\
\hline
\end{tabular}

$P<0.001, r=0.699,95 \%$ CI $[0.069,0.148])$ than negative photos $(0.11 \pm 0.02)$, whereas $K_{\text {false alarm rate }}$ did not differ between negative and neutral photos, $P>0.96$. Raw Remember and Know responses are summarized in Table 3.

Crucially, $98.85 \%$ of correct Remember responses (collapsed across negative and neutral stimuli) were accompanied by qualitative reports. Classified into three categories, participants' Remember responses were most often accompanied by intrinsic details $(56.20 \pm 2.99 \%)$ versus extrinsic details $(35.69 \pm 2.79 \%)$ versus emotional reaction $(6.95 \pm 1.05 \%)$; main effect of category: $\left(F_{(1.22,39.80)}=69.06, P<0.001, \eta^{2}=0.677\right)$. Out of the surprisingly small percentage of Remember responses justified with emotional reaction, participants reported significantly more often that the photo had elicited an emotional reaction during encoding for negative Remember hits $(9.34 \% \pm 1.54 \%)$ versus neutral Remember hits $\left(3.53 \pm 0.92 \% ; t_{(33)}=3.50, P<0.01, r=0.521,95 \%\right.$ CI $[2.436$, 9.178]).

Most critically, consistent with our hypothesis that memory for different types of details underlies the enhanced SSR for negative versus neutral stimuli, a significant Detail Type (Intrinsic/ Extrinsic) $\times$ Emotion (Negative/Neutral) interaction in a $2 \times 2$ ANOVA $\left(F_{(1,33)}=9.944, P \leq 0.01, \eta^{2}=0.231\right)$ showed that participants reported more intrinsic memory details for correct Remember responses for negative than neutral photos (emotional: $59.00 \pm 2.88 \%$ versus neutral: $50.80 \pm 4.32 \%) ; t_{(33)}=2.28, P<$ $0.05, r=0.369,95 \%$ CI $[0.894,15.491]$, Fig. 1). Inversely, participants reported more extrinsic details for correct Remember responses for neutral $(41.22 \pm 4.01 \%)$ than negative photos $(30.75 \pm$ $2.50 \% ; t_{(33)}=3.23, P<0.01, r=0.491,95 \%$ CI $[3.883,17.053]$; see Fig. 1). Importantly, correct Remember responses for negative stimuli were more often accompanied by memory of intrinsic details $(59.00 \pm 2.88 \%)$ than extrinsic details $\left(30.08 \pm 2.50 \%, t_{(33)}=5.49\right.$, $P<0.01, r=0.691,95 \%$ CI $[17.78,38.70])$. In contrast, for neutral stimuli, correct Remember responses were equally often accompanied by memory for intrinsic and extrinsic details $(P>0.22)$. This finding suggests that the enhanced SSR for negative photos was distinctly coupled to memory for intrinsic rather than extrinsic details.
In this study, we examined the relationship between subjective (SSR) and objective memory (intrinsic vs. extrinsic details vs. emotional reaction) for negative versus neutral stimuli. As expected, we replicated enhanced SSR for negative versus neutral stimuli (Ochsner 2000; Kensinger and Corkin 2003; Phelps and Sharot 2008).

Surprisingly, memory for the emotion experienced at encoding was not the main factor underlying the enhanced SSR, as the amount of correct Remember response that participants justified with their initial emotional reaction was rather small $(9.34 \%$ for emotional vs. $3.53 \%$ for neutral). Rather, correct Remember responses for negative stimuli were significantly more often accompanied with reports of memory for intrinsic or extrinsic detail than emotional reaction.

The novelty of our results lies in the finding that for emotional photos, SSR is linked more often to memory for intrinsic versus extrinsic details. In contrast, for neutral photos, the justifications for correct "Remember" responses were equally often accompanied by memories for intrinsic versus extrinsic details, consistent with previous findings of neutral Remember judgments being linked to various details (Perfect et al. 1996; Curran et al. 1997). These results may be explained by an emotioninduced modulation of memory encoding processes. Emotionally arousing stimuli attract attention (Anderson and Phelps 2001; Fox et al. 2001; Öhman et al. 2001; MacKay et al. 2004), enhance perception (Phelps et al. 2006; Bocanegra and Zeelenberg 2009; Todd et al. 2012), and increase sympathetic arousal (Anderson et al. 2006). Accordingly, our emotionally arousing stimuli might have captured and sustained attention differently than neutral stimuli (Vuilleumier et al. 2001; Pourtois et al. 2013), making it more likely that participants zoom in on the intrinsic aspects of the emotionally arousing parts of the scenes. Focused attention is required for perceptually binding intrinsic features to an item (Treisman 1999) and intrinsic item features may then be automatically integrated into working memory (Ecker et al. 2013). As such, more readily available attention together with increased access to working memory resources for emotional items at encoding may lead to increased binding of emotional

Table 3. Memory scores

\begin{tabular}{|c|c|c|c|c|}
\hline & \multicolumn{2}{|c|}{ Negative } & \multicolumn{2}{|c|}{ Neutral } \\
\hline & M & SE & M & SE \\
\hline$R_{\text {hit rate }}$ & 0.78 & 0.03 & 0.58 & 0.04 \\
\hline$\%$ of $R_{\text {hit rate justified with intrinsic details }}$ & 59.00 & 2.88 & 50.80 & 4.32 \\
\hline$\%$ of $R_{\text {hit rate justified with extrinsic details }}$ & 30.08 & 2.50 & 41.22 & 4.01 \\
\hline$\%$ of $R_{\text {hit rate justified with emotional reaction }}$ & 9.34 & 1.54 & 3.53 & 0.92 \\
\hline$R_{\text {fa rate }}$ & 0.014 & 0.004 & 0.01 & 0.005 \\
\hline$K_{\text {hit rate }}$ & 0.11 & 0.02 & 0.22 & 0.03 \\
\hline$K_{\text {fa rate }}$ & 0.06 & 0.01 & 0.06 & 0.01 \\
\hline Subjective recollection $\left(R_{\text {hit rate }}-R_{\text {fa rate }}\right)$ & 0.77 & 0.03 & 0.56 & 0.04 \\
\hline Familiarity $\left(K_{\text {hit rate }} /\left(1-R_{\text {hit rate }}\right)-\left(K_{\mathrm{fa}}\right.\right.$ rate $/\left(1-R_{\mathrm{fa}}\right.$ rate $)$ & 0.45 & 0.06 & 0.46 & 0.05 \\
\hline Overall recognition $\left(R_{\text {hit rate }}+K_{\text {hit rate }}\right)-\left(R_{\mathrm{fa}}\right.$ rate $+K_{\mathrm{fa}}$ rate $)$ & 0.90 & 0.02 & 0.80 & 0.02 \\
\hline
\end{tabular}




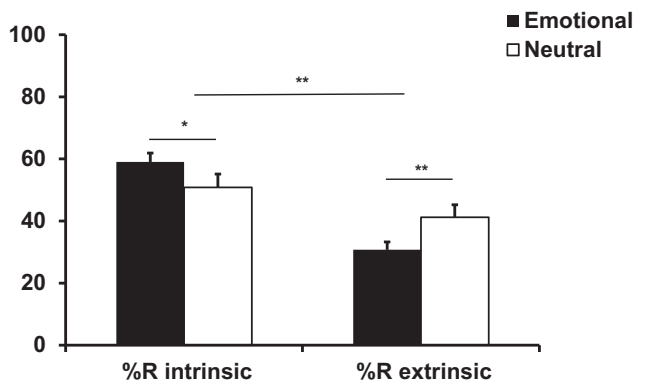

Figure 1. Correct Remember responses were more often accompanied by memory for intrinsic versus extrinsic details $(P<0.01)$. Crucially, the proportion of correct Remember responses that brought back an intrinsic detail was higher for negative versus neutral photos $(P<0.05)$. Contrariwise, correct Remember responses for negative photos were less often accompanied by memory for extrinsic detail $(P<0.01)$.

item's perceptual features and integration into long-term memory (Mather 2007).

These intrinsic contextual details are then more often recalled for emotional stimuli, and may lead participants to provide more often a Remember response to emotional versus neutral stimuli, as we found in the present study where participants reported more intrinsic memory details for Remember response for emotional versus neutral photos. At the neuronal level, the amygdala's dense neural connections to visual cortices and sensory areas could facilitate its role in recollection by reactivating the initial sensory representations and details associated with the emotional stimulus (Vuilleumier et al. 2004; Phelps and LeDoux 2005), causing individuals to relive the full extent of the episode and recall more intrinsic details for emotional stimuli at retrieval (Hofstetter et al. 2012). This, in turn, could explain why individuals feel their memory for emotional events to be more vivid as previously suggested (Phelps and Sharot 2008).

Our study shows for the first time that enhanced SSR for emotional versus neutral stimuli is linked to memory for intrinsic versus extrinsic details experienced at encoding. This holds important implications for eyewitness testimony that contain memory for details (Loftus and Palmer 1996). Importantly, timing, that is, stimulus presentation of $4 \mathrm{sec}$. together with a short ISI of $1 \mathrm{sec}$. in our study, could pose a limitation in our study in that participants may not have had enough time to experience an emotion or recall an extrinsic detail during encoding. Future studies should examine whether changing the time of stimulus presentation and ISI might change the proportion of later Remember justifications based on recall of intrinsic and extrinsic details and emotional reaction. In addition, future studies should aim at examining the neural correlates of intrinsic versus extrinsic recollection of detail for emotional versus neutral stimuli and their relation to the SSR using neuroimaging. A better understanding of this mechanism may provide insights into the mechanisms involved in traumatic memories, as one of the core symptoms of posttraumatic stress disorder (PTSD) is enhanced memory for the central traumatic event, which patients involuntarily relive in great detail in the form of intrusive memories (Bisby et al. 2010; Brewin et al. 2010).

\section{Acknowledgments}

This research was supported by a Bourse Théodore Flournoy 2018 (to M.M.), the Pierre Mercier Foundation (to U.R.), and the National Center of Competence in Research (NCCR) Affective Sciences and the Academic Society of Geneva (Foremane Fund). U.R. was supported by the Swiss National Science Foundation (PZ00P1_137126 and PZ00P1_160861) and the European
Community Seventh Framework Program (FP7/2007-2013) under grant agreement 334360.

\section{References}

Anderson AK, Phelps EA. 2001. Lesions of the human amygdala impair enhanced perception of emotionally salient events. Nature 411: 305309. doi: $10.1038 / 35077083$

Anderson AK, Yamaguchi Y, Grabski W, Lacka D. 2006. Emotional memories are not all created equal: evidence for selective memory enhancement. Learn Mem 13: 711-718. doi:10.1101/lm.388906

Antypa D, Vuilleumier P, Rimmele U. 2018. Suppressing but not intensifying emotion decreases arousal and subjective sense of recollection. Emotion. doi:10.1037/emo0000493

Bisby JA, Burgess N. 2014. Negative affect impairs associative memory but not item memory. Learn Mem 21: 21-27. doi:10.1101/lm.032409.113

Bisby JA, King JA, Brewin CR, Burgess N, Curran HV. 2010. Acute effects of alcohol on intrusive memory development and viewpoint dependence in spatial memory support a dual representation model. Biol Psychiatry 68: $280-286$. doi:10.1016/j.biopsych.2010.01.010

Bocanegra BR, Zeelenberg R. 2009. Emotion improves and impairs early vision. Psychol Sci 20: 707-713. doi:10.1111/j.1467-9280.2009.02354.x

Boywitt CD. 2015. Non-monotonic relationships between emotional arousal and memory for color and location. Cogn Emot 29: 1335-1349. doi:10.1080/02699931.2014.977850

Brewin CR, Gregory JD, Lipton M, Burgess N. 2010. Intrusive images in psychological disorders: characteristics, neural mechanisms, and treatment implications. Psychol Rev 117: 210-232. doi:10.1037/ a0018113

Curran T, Schacter DL, Norman KA, Galluccio L. 1997. False recognition after a right frontal lobe infarction: memory for general and specific information. Neuropsychologia 35: 1035-1049. doi:10.1016/S0028-3932 (97)00029-8

Deffenbacher KA. 1980. Eyewitness accuracy and confidence: can we infer anything about their relationship? Law Hum Behav 4: 243-260. doi:10 .1007/BF01040617

Dolcos F, LaBar KS, Cabeza R. 2005. Remembering one year later: role of the amygdala and the medial temporal lobe memory system in retrieving emotional memories. Proc Natl Acad Sci 102: 2626-2631. doi:10.1073/ pnas.0409848102

Ecker UKH, Maybery M, Zimmer HD. 2013. Binding of intrinsic and extrinsic features in working memory. J Exp Psychol Gen 142: 218-234. doi:10.1037/a0028732

Fox E, Russo R, Bowles R, Dutton K. 2001. Do threatening stimuli draw or hold visual attention in subclinical anxiety? J Exp Psychol Gen 130: 681700. doi:10.1037/0096-3445.130.4.681

Gardiner JM, Ramponi C, Richardson-Klavehn A. 1998. Experiences of remembering, knowing, and guessing. Conscious Cogn 7: 1-26. doi:10 $.1006 / \mathrm{ccog} .1997 .0321$

Hofstetter C, Achaibou A, Vuilleumier P. 2012. Reactivation of visual cortex during memory retrieval: content specificity and emotional modulation. Neuroimage 60: 1734-1745. doi:10.1016/j.neuroimage .2012 .01 .110

Kensinger EA. 2009. Remembering the details: effects of emotion. Emot Rev 1: $99-113$. doi:10.1177/1754073908100432

Kensinger EA, Corkin S. 2003. Memory enhancement for emotional words: are emotional words more vividly remembered than neutral words? Mem Cognit 31: 1169-1180. doi:10.3758/BF03195800

Lang PJ, Bradley MM, Cuthbert BN. 2005. International Affective Picture System (IAPS): affective ratings of pictures and instruction manual. Technical Report A-6, University of Florida, Gainesville, Florida.

Loftus EF, Palmer JC. 1996. Eyewitness testimony. In Introducing psychological research, pp. 305-309. Palgrave, London.

MacKay DG, Shafto M, Taylor JK, Marian DE, Abrams L, Dyer JR. 2004. Relations between emotion, memory, and attention: evidence from taboo stroop, lexical decision, and immediate memory tasks. Mem Cognit 32: 474-488. doi:10.3758/BF03195840

Marchewka A, Żurawski L, Jednoróg K, Grabowska A. 2014. The Nencki Affective Picture System (NAPS): introduction to a novel, standardized, wide-range, high-quality, realistic picture database. Behav Res Methods 46: 596-610. doi:10.3758/s13428-013-0379-1

Marin MM, Leder H. 2016. Effects of presentation duration on measures of complexity in affective environmental scenes and representational paintings. Acta Psychol (Amst) 163: 38-58. doi:10.1016/j.actpsy.2015.10 .002

Mather M. 2007. Emotional arousal and memory binding: an object-based framework. Perspect Psychol Sci 2: 33-52. doi:10.1111/j.1745-6916.2007 .00028.x

Mather M, Sutherland M. 2009. Disentangling the effects of arousal and valence on memory for intrinsic details. Emot Rev 1: 118-119. doi:10 $.1177 / 1754073908100435$ 
Ochsner KN. 2000. Are affective events richly recollected or simply familiar? The experience and process of recognizing feelings past. J Exp Psychol Gen 129: 242-261. doi:10.1037/0096-3445.129.2.242

Öhman A, Flykt A, Esteves F. 2001. Emotion drives attention: detecting the snake in the grass. J Exp Psychol Gen 130: 466-478. doi:10.1037/ 0096-3445.130.3.466

Perfect TJ, Mayes AR, Downes JJ, Van Eijk R. 1996. Does context discriminate recollection from familiarity in recognition memory? QJ Exp Psychol A 49: 797-813. doi:10.1080/713755644

Phelps EA, LeDoux JE. 2005. Contributions of the amygdala to emotion processing: from animal models to human behavior. Neuron 48: 175187. doi:10.1016/j.neuron.2005.09.025

Phelps EA, Sharot T. 2008. How (and why) emotion enhances the subjective sense of recollection. Curr Dir Psychol Sci 17: 147-152. doi:10.1111/j 1467-8721.2008.00565.x

Phelps EA, Ling S, Carrasco M. 2006. Emotion facilitates perception and potentiates the perceptual benefits of attention. Psychol Sci 17: 292-299. doi:10.1111/j.1467-9280.2006.01701.x

Pourtois G, Schettino A, Vuilleumier P. 2013. Brain mechanisms for emotional influences on perception and attention: what is magic and what is not. Biol Psychol 92: 492-512. doi:10.1016/j.biopsycho.2012.02 .007

Rajaram S. 1993. Remembering and knowing: two means of access to the personal past. Mem Cognit 21: 89-102. doi:10.3758/BF03211168

Rimmele U, Davachi L, Petrov R, Dougal S, Phelps EA. 2011. Emotion enhances the subjective feeling of remembering, despite lower accuracy for contextual details. Emotion 11: 553-562. doi:10.1037/a0024246

Rimmele U, Davachi L, Phelps EA. 2012. Memory for time and place contributes to enhanced confidence in memories for emotional events. Emotion 12: 834-846. doi:10.1037/a0028003

Rimmele U, Lackovic SF, Tobe RH, Leventhal BL, Phelps EA. 2016. Beta-adrenergic blockade at memory encoding, but not retrieval, decreases the subjective sense of recollection. J Cogn Neurosci 28: 895907. doi:10.1162/jocn_a_00941

Sharot T, Yonelinas AP. 2008. Differential time-dependent effects of emotion on recollective experience and memory for contextual information. Cognition 106: 538-547. doi:10.1016/j.cognition.2007.03 .002

Sharot T, Delgado MR, Phelps EA. 2004. How emotion enhances the feeling of remembering. Nat Neurosci 7: 1376-1380. doi:10.1038/nn1353

Sharot T, Martorella EA, Delgado MR, Phelps EA. 2007a. How personal experience modulates the neural circuitry of memories of September 11. Proc Natl Acad Sci 104: 389-394. doi:10.1073/pnas.0609230103

Sharot T, Verfaellie M, Yonelinas AP. 2007b. How emotion strengthens the recollective experience: a time-dependent hippocampal process. PLoS One 2: e1068. doi:10.1371/journal.pone.0001068

Talarico JM, Rubin DC. 2003. Confidence, not consistency, characterizes flashbulb memories. Psychol Sci 14: 455-461. doi:10.1111/1467-9280 .02453

Todd RM, Talmi D, Schmitz TW, Susskind J, Anderson AK. 2012. Psychophysical and neural evidence for emotion-enhanced perceptual vividness. J Neurosci 32: 11201-11212. doi:10.1523/JNEUROSCI .0155-12.2012

Treisman A. 1999. Solutions to the binding problem: progress through controversy and convergence. Neuron 24: 111-125. doi:10.1016/ S0896-6273(00)80826-0

Tulving E. 1985. Memory and consciousness. Can Psychol 26: 1-12. doi:10 $.1037 / \mathrm{h} 0080017$

Vuilleumier P, Armony JL, Driver J, Dolan RJ. 2001. Effects of attention and emotion on face processing in the human brain: an event-related fMRI study. Neuron 30: 829-841. doi:10.1016/S0896-6273(01)00328-2

Vuilleumier P, Richardson MP, Armony JL, Driver J, Dolan RJ. 2004. Distant influences of amygdala lesion on visual cortical activation during emotional face processing. Nat Neurosci 7: 1271-1278. doi:10.1038/ nn1341

Yovel G, Paller KA. 2004. The neural basis of the butcher-on-the-bus phenomenon: when a face seems familiar but is not remembered. Neuroimage 21: 789-800. doi:10.1016/j.neuroimage.2003.09.034

Received March 15, 2019; accepted in revised form August 13, 2019. 


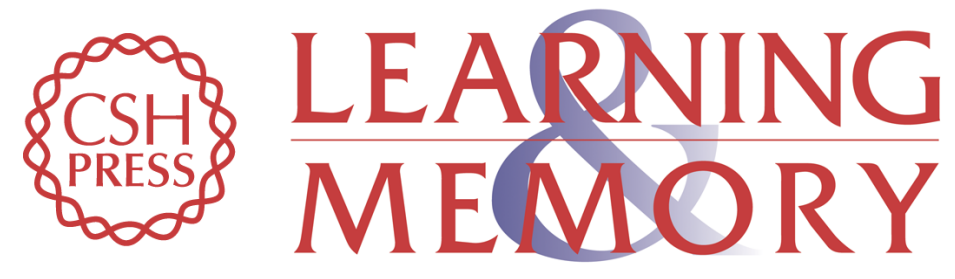

\section{Better memory for intrinsic versus extrinsic details underlies the enhanced recollective experience of negative events}

Mariela Mihaylova, Patrik Vuilleumier and Ulrike Rimmele

Learn. Mem. 2019, 26:

Access the most recent version at doi:10.1101/Im.049734.119

References This article cites 44 articles, 5 of which can be accessed free at:

http://learnmem.cshlp.org/content/26/11/455.full.html\#ref-list-1

Creative This article is distributed exclusively by Cold Spring Harbor Laboratory Press for the

Commons first 12 months after the full-issue publication date (see

License http://learnmem.cshlp.org/site/misc/terms.xhtml). After 12 months, it is available under a Creative Commons License (Attribution-NonCommercial 4.0 International), as described at http://creativecommons.org/licenses/by-nc/4.0/.

Email Alerting Receive free email alerts when new articles cite this article - sign up in the box at the Service top right corner of the article or click here. 